\title{
The measurement of food iron absorption in man
}

\section{A methodological study on the measurement of dietary non-haem-Fe absorption when the subjects have a free choice of food items}

\author{
BY L. HALLBERG, E. BJÖRN-R ASMUSSEN AND L. ROSSANDER \\ Department of Medicine II, Sahlgrenska sjukhuset, University of Göteborg, \\ S-4I3 45 Göteborg, Sweden \\ AND R. SUWANIK \\ Department of Radiology, Siriraj Hospital, Madihol University, \\ Bangkok 7, Thailand
}

(Received Io February 1978 - Accepted II October 1978)

\begin{abstract}
I. The present study was considered as a first step to develop a method to measure food iron absorption from realistic common meals prepared and consumed by the subjects themselves in their own homes. The absorption of Fe from the meals was measured by means of the extrinsic-tag method modified to allow for a free choice of food items.

2. The mean $\mathrm{Fe}$ intake was $2.79 \mathrm{mg}$ and the mean Fe absorption approximately $0.30 \mathrm{mg}$. The Fe status of the subjects corresponded to $31 \cdot 5 \%$ absorption from a reference dose solution containing $3 \mathrm{mg}$ elemental $\mathrm{Fe}$ as ferrous ascorbate. The variation in food Fe absorption obtained in this field study was found to be of the same magnitude as that obtained in studies performed under more controlled conditions as in the laboratory.

3. The conclusion was drawn that the proposed method could be used in realistic field studies aimed at, for example, explaining or preventing a high prevalence of deficiency. A sufficiently long run-in period and a careful instruction of the subjects was considered essential for the design of future field studies.
\end{abstract}

In populations with a high prevalence of iron deficiency there is a need to know how much $\mathrm{Fe}$ is absorbed from the diet and how much more Fe will be absorbed if the diet is modified, for example, by the introduction of an Fe-fortification programme.

It is well known that a number of factors influence the absorption of Fe from a meal. Studies on the role of the diet in explaining a certain prevalence of Fe deficiency or on the feasibility of increasing the absorption by certain measures should therefore be carried out under as realistic conditions as possible.

Recently an extrinsic-tag method has been developed and validated for measurement of Fe absorption from composite meals (Hallberg \& Björn-Rasmussen, I 972 ; Björn-Rasmussen et al. 1976). Previous studies in which this method was used to measure $\mathrm{Fe}$ absorption were made on meals with a certain fixed composition in each series (Cook et al. 1972; Layrisse \& Martinez-Torres, 1972; Björn-Rasmussen et al. 1974).

When applying the extrinsic-tag technique on freely-chosen meals a number of practical details and methodological problems have to be considered. One purpose of this study was to test the practical applicability of the extrinsic-tag technique for measuring the $\mathrm{Fe}$ absorption from freely-chosen meals. Another purpose was to measure the variation in absorption of $\mathrm{Fe}$ on different days in subjects offered a free choice of food. This latter knowledge is needed for optimal design of future field studies on Fe absorption from the diet. 


\section{EXPERIMENTAL}

\section{Subjects}

Twenty subjects (sixteen men and four women, aged between 22 and $4 \mathrm{I}$ years) took part in the study. The subjects were mainly labourers living in the district of Bang Khun Tian on the outskirts of Bangkok. During the $5 \mathrm{~d}$ of the absorption study the subjects went to the headman's house at $\mathbf{1} 2.00$ hours and were served a midday meal.

\section{Experimental design}

Freshly-prepared food was brought to the house of the headman where it was served. Five items were offered: rice, vegetables, curry, fish and soup. The subjects were allowed to choose their meals from the foods offered and all foods taken were weighed. The meals were labelled by adding known amounts of a solution of radio-Fe and mixing it into the rice part of the meal. On day I no labelling was performed. This day was used as a 'run-in' day for the various procedures. On days 2 and 5 and on days 3 and $4{ }^{55} \mathrm{Fe}$ and ${ }^{59} \mathrm{Fe}$ respectively were used to label the non-haem-Fe of the meals.

At 2 weeks after serving the final labelled meal a blood sample was taken to determine the absorption of ${ }^{55} \mathrm{Fe}$ and ${ }^{59} \mathrm{Fe}$. A reference dose solution of ferrous ascorbate containing $3 \mathrm{mg}$ elemental $\mathrm{Fe}$ was then given on an empty stomach on two consecutive mornings. After another 2 weeks an additional blood sample was taken to determine the Fe absorption from the reference dose.

\section{Preparation of the food}

All foods were freshly prepared and cooked each day in the kitchen at Siriraj Hospital in Bangkok and transported in containers to the village of Bang Bon just before serving.

Rice. Polished patna rice was washed once in ordinary tap-water and boiled in a steam cooker $\left(0.5 \mathrm{~kg} / \mathrm{cm}^{2}, 25-30 \mathrm{~min}\right)$.

Vegetables. Swamp cabbage (Pak Boong; Ipomoea aquatica) was washed, cut into pieces and boiled in water for a few minutes.

Fish. Swamp fishes (Pla Chon; Ophicephalus stiatus) were gutted, cut into $20-50 \mathrm{~mm}$ pieces and cooked in water in the usual way. Bergamot (Kaffir lime) was added until the soup was considered to have a pleasant odour. The soup was seasoned with fish sauce (Nam Pla), lemon juice and pounded green chilli pepper (Capsicum fratescens). The fish and soup were then separated and served as two separate items.

Curry. Curry was prepared by pounding garlic (Allium savitum) without peel, small salted and fermented shrimps (Atyidae) and chilli pepper in a stone mortar. Fish sauce, lemon juice and jaggery (a kind of sugar) were thoroughly mixed together and then added.

The Fe content of all the items except fish was analysed on all $5 \mathrm{~d}$ of the experiment. Fish was analysed only once, because of the small variation in Fe content. The methods used have been described previously (Björn-Rasmussen et al. 1974).

\section{Serving of meals}

The subjects were instructed to eat their breakfast as usual in the morning. At 12.00 hours, when the subjects usually had their lunch, they were to go to the house of the headman. A midday meal was served on five consecutive days in the following way: containers with the different food items were placed on a table. The subjects were asked to take as much as they wanted but were also told to avoid leaving any. All the items taken by the subjects were weighed on a direct-reading balance (Mettler E I000). Rice was taken on a separate dish. The rice was labelled with radio-Fe by adding dropwise $1 \mathrm{ml}$ of a solution of radioactive ferric chloride in $\mathrm{O} \cdot \mathrm{I}$ M-hydrochloric acid onto the rice by means of an Eppendorf 
Table I. Mean intake ( $\mathrm{g}$ ) of food items*, the variation in Fe content $(\mathrm{mg} / \mathrm{kg}$ ) of the food items and the mean $\mathrm{Fe}$ intake ( $\mathrm{mg}$ ) on different days by adult subjects having a free choice of food items.

(Values in parentheses indicate relative contribution of each item to complete meal)

\begin{tabular}{|c|c|c|c|c|c|c|}
\hline \multirow[b]{2}{*}{ Rice. } & \multicolumn{6}{|c|}{ Day } \\
\hline & I & 2 & 3 & 4 & 5 & $1-5$ \\
\hline$W t$ & 306 & 350 & 287 & 343 & 287 & 315 \\
\hline Fe content & 2.5 & $1 \cdot 7$ & I.9 & $\mathrm{I} \cdot 7$ & $2 \cdot 0$ & $2 \cdot 0$ \\
\hline $\mathrm{Fe}$ intake & 0.76 & 0.59 & 0.55 & 0.58 & 0.57 & $0.63(23)$ \\
\hline Vegetables: & & & & & & \\
\hline Wt & 33 & 38 & $4 \mathrm{I}$ & 44 & 36 & 38 \\
\hline $\mathrm{Fe}$ content & 10.8 & 15.2 & II 0 & II $\cdot I$ & $12 \cdot 6$ & I 2.I \\
\hline $\mathrm{Fe}$ intake & 0.36 & 0.58 & 0.45 & 0.48 & 0.45 & $0.46(16)$ \\
\hline Curry: & & & & & & \\
\hline $\mathrm{Wt}$ & 14 & 18 & 13 & I5 & 13 & 15 \\
\hline Fe content & $56 \cdot 6$ & $73 \cdot 2$ & $63 \cdot 3$ & $68 \cdot 3$ & $55 \cdot \mathrm{I}$ & $63 \cdot 3$ \\
\hline Fe intake & 0.80 & $\mathrm{I} \cdot 28$ & 0.83 & 1.05 & 0.72 & $0.93(33)$ \\
\hline Soup: & & & & & & \\
\hline Wt & 94 & I 25 & 104 & 92 & 82 & 100 \\
\hline $\mathrm{Fe}$ content & 5.4 & $7 \cdot 8$ & $2 \cdot 8$ & $2 \cdot 0$ & $\mathrm{I} \cdot 2$ & 3.8 \\
\hline Fe intake & 0.51 & 0.97 & 0.29 & 0.18 & 0.10 & $0.38(14)$ \\
\hline Fish: & & & & & & \\
\hline Wt & 86 & 58 & 53 & 60. & 52 & 61 \\
\hline $\mathrm{Fe}$ content & $6 \cdot 3$ & $6 \cdot 3$ & $6 \cdot 3$ & $6 \cdot 3$ & $6 \cdot 3$ & $6 \cdot 3$ \\
\hline Fe intake & 0.54 & 0.36 & 0.33 & 0.38 & 0.32 & 0.39 (14) \\
\hline The complete & & & & & & \\
\hline $\mathrm{Wt}$ & & 588 & & 554 & 469 & 529 \\
\hline Fe intake & $\begin{array}{r}5.3 .97 \\
2.97\end{array}$ & 3.78 & 2.45 & 2.67 & $2 \cdot 16$ & $2 \cdot 79(100)$ \\
\hline
\end{tabular}

pipette. The portion of rice was then mixed with a glass rod. The other food items were chosen and weighed and the meal was then consumed in a way similar to the subjects' usual way of eating. The subjects were given plenty of time both to select and to eat their food. No food was left. Water was freely available with the meals.

\section{Absorption measurements}

The food-Fe absorption was measured by means of the extrinsic-tag method; $5 \mu \mathrm{Ci}$ ${ }^{65} \mathrm{Fe}$ and $2.5 \mu \mathrm{Ci}{ }^{59} \mathrm{Fe}$ were used as extrinsic tracers of $\mathrm{Fe}$ absorption. The meals served on days 2 and 5 were labelled with ${ }^{55} \mathrm{Fe}$, and the meals served on days 3 and 4 with ${ }^{59} \mathrm{Fe}$. The absorption of the two tracers was calculated from the radioactivity found in the blood samples taken 2 weeks after the final test meal. The amount of Fe absorbed was then calculated from the total $\mathrm{Fe}$ intake as calculated from food-Fe analysis and the food-weight records.

Each of the two reference doses of $3 \mathrm{mg} \mathrm{Fe}$ as ferrous ascorbate given to each subject was labelled with $7 \mu \mathrm{Ci}{ }^{55} \mathrm{Fe}$. The absorption of the reference dose was calculated from the uptake of radio-Fe into blood in the sample taken 2 weeks after the reference doses were given. 
Table 2. Intake of food items $(g)^{*}$ and $\mathrm{Fe}(\mathrm{mg})$ on days $\mathrm{I}-5$ by adult subjects having a free choice of food items

(Values are means with their standard errors)

\begin{tabular}{|c|c|c|c|c|c|c|c|c|c|c|c|c|}
\hline \multirow{2}{*}{$\begin{array}{l}\text { Sub- } \\
\text { ject }\end{array}$} & \multirow[b]{2}{*}{ Sex } & \multicolumn{2}{|c|}{ Rice } & \multicolumn{2}{|c|}{ Vegetables } & \multicolumn{2}{|c|}{ Curry } & \multicolumn{2}{|c|}{ Soup } & \multicolumn{2}{|c|}{ Fish } & \multirow{2}{*}{$\begin{array}{l}\text { Total } \\
\text { iron } \\
\text { intake }\end{array}$} \\
\hline & & Mean & SE & Mean & $\mathrm{SE}$ & Mean & SE & Mean & SE & Mean & SE & \\
\hline I & Male & 266 & 25 & 40 & 9 & 10 & 5 & 97 & 18 & 6I & 34 & $2 \cdot 42$ \\
\hline 2 & Male & 426 & 189 & 43 & 4 & I4 & 8 & 115 & 34 & & 23 & $3 \cdot 15$ \\
\hline 3 & Female & 202 & 56 & & & II & 6 & 88 & 40 & 2 & 14 & I. 49 \\
\hline 4 & Male & 359 & 56 & & & & & I 2 I & 44 & 78 & 10 & $1 \cdot 73$ \\
\hline 5 & Male & 318 & 60 & 49 & 9 & I 2 & 3 & 140 & 23 & 75 & 16 & 3.01 \\
\hline 6 & Male & $34 \mathrm{I}$ & 192 & 37 & I0 & 13 & 2 & I 33 & 50 & 7 & 23 & 2.98 \\
\hline 7 & Female & & 45 & 28 & I6 & 14 & 2 & 74 & 18 & 9 & 17 & $2 \cdot 20$ \\
\hline 8 & Fems & 250 & 91 & 20 & 23 & 18 & 7 & 87 & 7 & I & 24 & $2 \cdot 45$ \\
\hline 9 & Female & 213 & 66 & 21 & 5 & 15 & 4 & 82 & 25 & 3 & 18 & $2 \cdot 23$ \\
\hline 10 & Male & & 28 & 31 & I2 & 12 & 5 & 123 & 32 & & 14 & $2 \cdot 45$ \\
\hline II & Male & 462 & $8 I$ & 71 & 17 & 25 & 5 & 89 & II & 62 & 13 & 4.06 \\
\hline 12 & Male & 362 & 97 & 45 & I5 & 16 & 3 & 80 & $3 \mathrm{I}$ & & 23 & $2 \cdot 95$ \\
\hline 13 & Male & 442 & 140 & 39 & I 2 & 13 & 3 & II 2 & 44 & 0 & 12 & $2 \cdot 84$ \\
\hline 14 & $\mathrm{Ma}$ & 33 & 55 & 45 & 8 & 18 & 5 & II 7 & 26 & & 14 & $3 \cdot 16$ \\
\hline 15 & Male & 31 & 48 & 53 & 8 & I3 & 5 & 75 & $2 \mathrm{I}$ & & 8 & $2 \cdot 67$ \\
\hline 16 & Male & 437 & 94 & 55 & 8 & 17 & 4 & 78 & $3 \mathrm{I}$ & 74 & 23 & $3 \cdot 38$ \\
\hline 17 & $\mathrm{Mal}$ & & 40 & 42 & I3 & $3 \mathrm{I}$ & 3 & 62 & & 57 & 13 & 3.61 \\
\hline 18 & $\mathrm{Ma}$ & 269 & 73 & 51 & I I & 17 & 3 & 82 & 22 & 49 & 5 & $2 \cdot 83$ \\
\hline 19 & Male & 288 & 80 & 46 & 15 & 23 & 8 & 127 & 38 & 59 & 14 & 3.43 \\
\hline 20 & Male & 346 & 59 & 76 & 18 & 7 & 2 & 102 & 19 & 70 & 9 & $2 \cdot 84$ \\
\hline $\mathrm{Mea}$ & & 315 & & 38 & & I5 & & 100 & & $6 \mathrm{I}$ & & $2 \cdot 79$ \\
\hline
\end{tabular}

* For details of composition and preparation, see p. 284.

\section{RESULTS}

The mean intake of food items, the variation in Fe content of the food items and the mean $\mathrm{Fe}$ intake on different days are shown in Table $\mathrm{I}$. The mean meal weight was $529 \mathrm{~g}, 315 \mathrm{~g}$ of which was rice and $\mathrm{I} 6 \mathrm{I} \mathrm{g}$ fish and soup. As a whole, the variation in food intake was not very marked. There was, however, a considerable variation in the Fe content of the food items. Most of the Fe, $0.9 \mathrm{mg}(33 \%)$ came from the curry, which also had the highest $\mathrm{Fe}$ content $(63 \mathrm{mg} / \mathrm{kg})$. The second highest source of $\mathrm{Fe}$ was the rice, which contributed $0.6 \mathrm{mg} \mathrm{Fe}(23 \%)$.

The mean intake of the five food items and its variation between subjects on days $I-5$ is shown in Table 2. As expected, the women had a somewhat lower intake of food and $\mathrm{Fe}$ than the men. The mean intake of Fe from the meals was $2.79 \mathrm{mg}$ and the mean energy intake was $18 \mathrm{r} 8 \mathrm{~kJ}$ ( $435 \mathrm{kcal})$.

The absorption of food $\mathrm{Fe}$ on days $2+5$ and days $3+4$ and the absorption of the reference dose is shown in Table 3. There was good agreement between the food-Fe absorption values for the two periods. The disagreement in subject no. 7 cannot be explained. The relationship between food-Fe absorption for the two periods is shown in Fig. I.

\section{DISCUSSION}

One of the main difficulties in studies on Fe absorption is the great variation in absorption not only between different subjects, due to differences in Fe status, but also between different days in the same subject. In studies on Fe absorption from composite meals further sources of error are introduced. In earlier studies the meal size and the volume of drink taken with 
Table 3. Absorption of Fe from meals* and reference dose by adult subjects having a free choice of food items

\begin{tabular}{|c|c|c|c|c|c|}
\hline \multirow[b]{3}{*}{ Subject } & \multicolumn{4}{|c|}{ Absorption from meals on day } & \multirow{3}{*}{$\begin{array}{l}\text { Absorption } \\
\text { from reference } \\
\text { dose } \\
(\%)\end{array}$} \\
\hline & \multicolumn{2}{|c|}{$2+5$} & \multicolumn{2}{|c|}{$3+4$} & \\
\hline & $(\%)$ & (mg) & $(\%)$ & (mg) & \\
\hline I & $9 \cdot 3$ & 0.14 & $6 \cdot 0$ & 0.07 & I6.7 \\
\hline 2 & $20 \cdot 0$ & 0.77 & $22 \cdot 4$ & 0.51 & 65.9 \\
\hline 3 & 4.6 & 0.11 & 9.9 & 0.12 & $12 \cdot 0$ \\
\hline 4 & I $4 * 4$ & 0.29 & $14 \cdot 6$ & 0.20 & $6 \cdot 7$ \\
\hline 5 & $18 \cdot 1$ & 0.59 & $17 \cdot 1$ & 0.49 & $59 \cdot 0$ \\
\hline 6 & $I I \cdot 2$ & 0.37 & $10 \cdot 9$ & 0.26 & $14 \cdot 1$ \\
\hline 7 & $7 \cdot 6$ & 0.18 & $25 \cdot 2$ & 0.48 & 67.6 \\
\hline 8 & 15.8 & 0.41 & $18 \cdot 0$ & 0.44 & $59 \cdot 2$ \\
\hline 9 & $4 \cdot 8$ & 0.12 & $3 \cdot 7$ & 0.08 & $17 \cdot 2$ \\
\hline 10 & $26 \cdot 4$ & 0.69 & $27 \cdot 4$ & 0.60 & 48.9 \\
\hline I I & 43 & 0.17 & 4.3 & 0.18 & 10.3 \\
\hline 12 & $2 \cdot 4$ & 0.07 & $3 \cdot 2$ & 0.08 & $9 \cdot 9$ \\
\hline 13 & 15.1 & 0.48 & 10.8 & 0.30 & 62.6 \\
\hline 14 & 22.9 & 0.85 & 20.6 & 0.53 & $68 \cdot 0$ \\
\hline 15 & 8.4 & 0.26 & 10.7 & 0.24 & $12 \cdot 2$ \\
\hline 16 & 5.8 & 0.20 & 4.9 & 0.17 & 3.2 \\
\hline 17 & 3.6 & 0.12 & 2.6 & 0.10 & 49.4 \\
\hline 18 & 5.5 & 0.14 & $5 \cdot 3$ & 0.16 & 16.5 \\
\hline 19 & $6 \cdot 1$ & 0.20 & 5.4 & 0.19 & I $8 \cdot 1$ \\
\hline \multirow[t]{3}{*}{20} & 9.5 & 0.27 & 12.7 & 0.36 & $11 \cdot 8$ \\
\hline & 10.8 & 0.32 & II $\cdot 8$ & 0.28 & $3 I \cdot 5$ \\
\hline & I. 56 & 0.05 & $I \cdot 73$ & 0.04 & 5.51 \\
\hline
\end{tabular}

* For details of composition and preparation, see p. 284 .

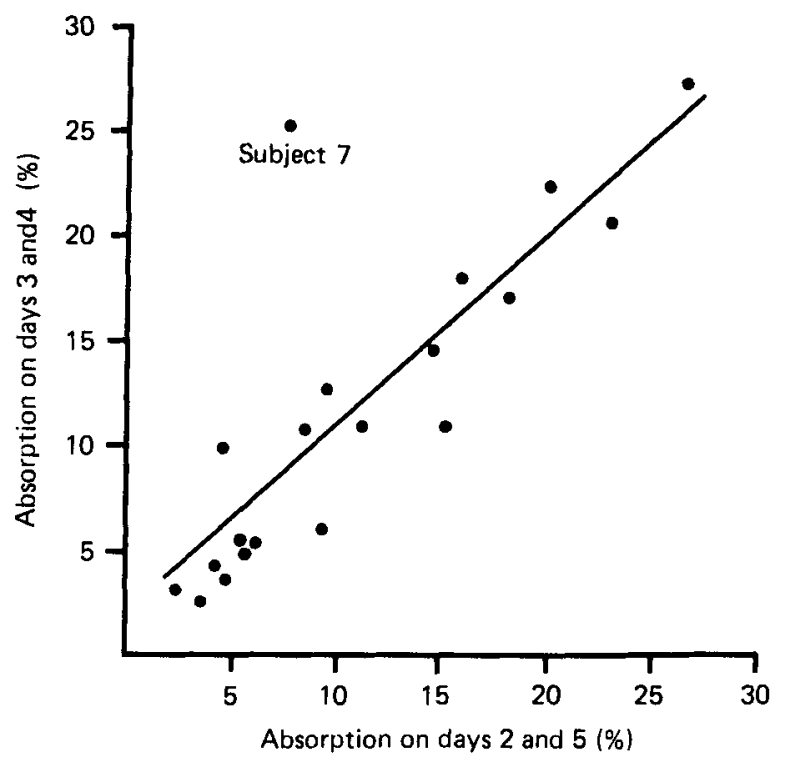

Fig. I. Relationship between iron absorption measurements from meals served on days $3+4$ and $2+5$ respectively to admit subjects given a free choice of five food items daily at 12.00 hours for $5 \mathrm{~d}$ (for details, see p. 284). 
the meal were kept constant to minimize the variation in absorption. For the same reason, the meals were served on an empty stomach in the morning.

In 'real life' there may be a marked variation in meal size, composition of meals, the volume of drink taken with the food etc. In order to make more realistic estimates of the absorption of $\mathrm{Fe}$ from the diet it is necessary to obtain knowledge about the absolute absorption of $\mathrm{Fe}$ from freely-chosen meals and the magnitude of variation in absorption.

The present study was carried out as a first step in this direction. In order to facilitate interpretation of the results, some sources of variation were eliminated. First, the choice of food was limited to five items commonly eaten by the population studied. Secondly, all the food was prepared at one place (Siriraj Hospital kitchen).

One of the main findings in the present study was the unexpectedly small variation in absorption on different days. The real variation was probably even smaller than that observed, because the meals were served at $\mathrm{2} 2.00$ hours and the subjects were told to eat their breakfast as usual in the morning. This instruction was probably followed by everyone except on days 2 and 5. Owing to some mistake in the instructions, many subjects ate no breakfast on the morning of day 2 and were thus in a fasting state at 12.00 hours when the meal was served. This is probably the reason why the average size of the meals was greater on that day. On the last day of the study (day 5) there were a few subjects who, also owing to some mistake in the instructions, had eaten a light meal just before I 2.00 hours. The meal size in these subjects on day 5 was therefore somewhat smaller. It is reasonable to assume that these systematic errors increased the measured variation in absorption of $\mathrm{Fe}$ on different days.

In subject no. 7 there was a very marked difference in absorption for the two periods (days $2+5$ and days $3+4$ ) compared with the results for the other subjects. We have no explanation for this. The lower absorption value was probably falsely low, judged by the absorption of the reference doses. As shown in Fig. I, there was very good agreement in absorption for the two periods in the other subjects. The correlation coefficient for all subjects was 0.83 . Excluding subject no. 7 , in whom the consistency in results differed greatly from all other subjects, as discussed previously, the correlation coefficient was 0.95 . The part of the variation which cannot be explained by the correlation $\left(1-r^{2}\right)$ is a good measure of the accuracy of the procedure used. This over-all variation, including experimental errors, was thus $9 \%$.

In studies on the variation in absorption from identical composite meals given on repeated occasions and labelled with different radio-Fe isotopes, the coefficient of variation was $8 \%$ (Björn-Rasmussen et al. 1976). The variation observed in the present study was not much greater, if one considers the further sources of variation related to differences in size and composition of meals, differences in specific radioactivity of the labelled meals served on different days and the possible systematic errors discussed previously which were inherent in the method.

In this study I $d$ was used as a 'run-in' day to allow the subjects to become accustomed to the experimental procedure. It was evident that a longer 'run-in' period is desirable (probably $3-4$ d) to ensure even better co-operation and to reduce the effect of the experimental situation.

Fasting conditions are essential when measuring the absorption from reference doses. The relationship between food-Fe absorption and absorption of the reference dose is shown in Fig. 2. In some subjects the absorption (\%) values for food and reference dose absorption are almost equal (subjects nos. 3, 4, 6, 15, I6 and 20). There is thus good reason to assume that these subjects were not in a fasting state when taking the reference dose but that they had consumed food with similar composition to the meals served. The reference doses would then act more or less as an extrinsic labelling of the food. This may be the reason for 


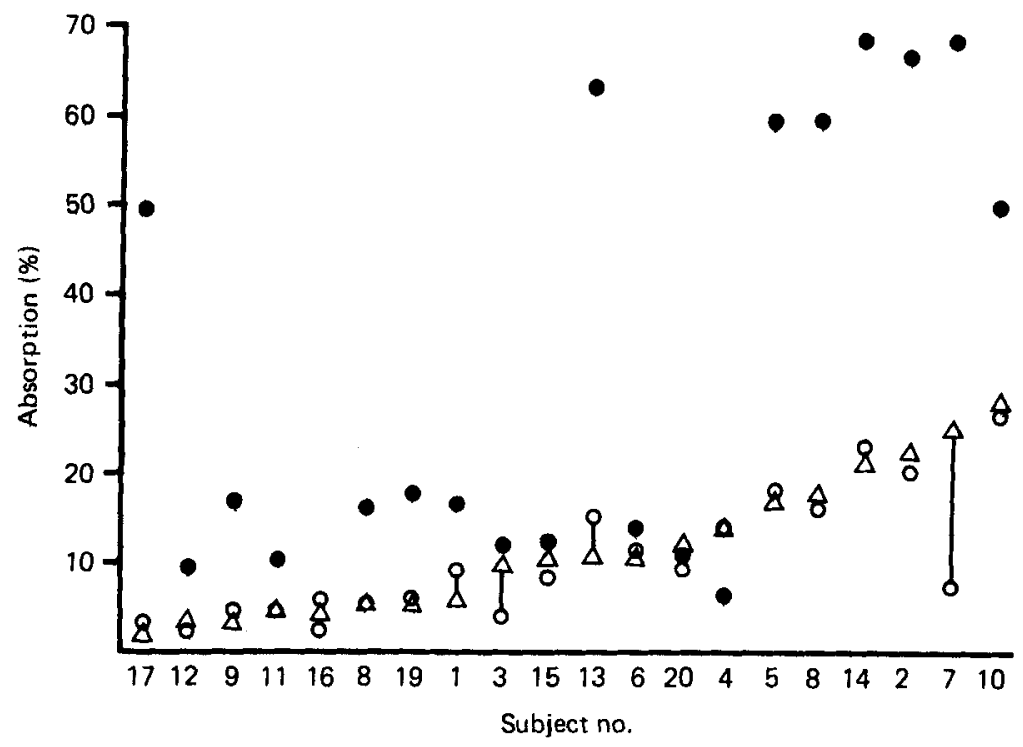

Fig. 2. Relationship between food-iron absorption and absorption of a reference dose $(3 \mathrm{mg}$ ferrous ascorbate) in adult subjects given a feee choice of five food items daily at 12.00 hours for $5 \mathrm{~d}$ (for details see p. 284). The subjects are presented in order of increasing absorption of the meals labelled with ${ }^{39} \mathrm{Fe}$ and served on days 3 and 4 . (O) reference dose; (O) meals labelled with ${ }^{55} \mathrm{Fe}$; $(\triangle)$ meals labelled with ${ }^{59} \mathrm{Fe}$. Vertical lines are connecting the two symbols $(O)$ and $(\triangle)$ representing absorption of food iron.

the low extent of correlation between food-Fe absorption and reference dose-Fe absorption found in this study $(r 0.63)$, in contrast to the much higher correlations found in previous studies (Björn-Rasmussen et al. 1976). The main conclusion of the present study is that the reproducibility of the method used is good and that it can be used in realistic field studies on $\mathrm{Fe}$ absorption from meals prepared by the subjects themselves. Certain modifications may be of value, however, e.g. a longer 'run-in' period.

The question to be answered by measurements of the absorption from freely-chosen meals in a field study is not how much $\mathrm{Fe}$ is absorbed by a certain individual but by a representative group of subjects or by subjects consuming a diet which is representative of, for instance, the target population of a fortification programme or by both groups. The final design of such studies (number of subjects, days, meals, etc.) depends on a number of factors, for example, the variation of the dietary habits in a population and the purpose of the study.

\section{REFERENCES}

Björn-Rasmussen, E., Hallberg, L., Isaksson, B. \& Arvidsson, B. (1974). J. clin. Invest. 53, 247.

Björn-Rasmussen, E., Hallberg, L., Magnusson, B., Rossander, L., Svanberg, B. \& Arvidsson, B. (I976). Am. J. clin. Nutr. 29, 772.

Cook, J. D., Layrisse, M., Martinez-Torres, C., Walker, R., Monsen, E. \& Finch. C. A. (I972). J. clin. Invest. 5x, 805 .

Hallberg, L. \& Björn-Rasmussen, E. (1972). Scand. J. Haemat. 9, 193.

Layrisse, M. \& Martinez-Torres, C. (1972). Am. J. clin. Nutr. 25, 401. 